\title{
Predict organizational citizenship behavior of the staff based on the factors of the job satisfaction
}

\author{
Khaidan HATAMI, Mohhammad Reza ESMAEILI, Sayed Hamid SAJADI
}

Department of Physical Education, Islamic Azad University, Tehran Center Branch, Tehran, Iran.

Address Correspondence to K. Hatami, e-mail: hatami.khid@gmail.com

\begin{abstract}
The aim of the present study was to predict organizational citizenship behavior of the staff of the Ministry of Sport and Youth in the west part of the country based on the factors of the Job Satisfaction. The research methodology employed was applied and practical. The population of the research consisted of all employees in the departments of the ministry of Sport and Youth in the west part of the country in the year 1394 including 266 personnel among whom 164ones were selected as research samples. In order to collect information, for collecting data on Job Satisfaction variable, the Standard Job Satisfaction questionnaire of Minnesota was used, and to collect data on the organizational citizenship behavior variable, the organizational citizenship behavior questionnaire of Podsakoff et al. was used. For data analysis, Kolmogorov-Smirnov inferential statistics was used to determine the normal distribution of data and the analysis of variance. For all Statistical Activities, SPSS statistical software version 22 with the confidence level 95\% was used. The research results showed that there was a significant relationship between Job Satisfaction and its components and organizational citizenship behavior. And the examination of the predictor variables showed that organizational climate can significantly explain the citizenship behavior variance.
\end{abstract}

Keywords: Job satisfaction, organizational citizenship behavior, staff of the ministry of sport and youth.

\section{INTRODUCTION}

Focusing on human force behaviors to achieve organizational excellence and objectives, organizational behavior management $(\mathrm{OBM})$ is an important and interested aspect of management in recent decades that aims at improving individual and organizational performance. Organizational citizenship behavior (OCB) is a concept which is considered as one of the major issues in the field of organizational behavior. Organizational citizenship behavior tends to take some important steps by providing strategies in order to enhance organizational commitment, performance improvement, customer satisfaction and job satisfaction, to name a few. Accordingly, organizational citizenship behavior is of interest and it is regarded as one of the imperative resources of almost any organization (3).

The concept of organizational citizenship behavior was first introduced by Organ \& Konovsky (17). Initial studies in the field of organizational citizenship behavior tended to identify the responsibilities and behaviors that employees took in organizations while they were often ignored.
These behaviors were either often incompletely measured in traditional assessments of job performance, or even sometimes totally neglected; though, they are influential in improving organizational effectiveness (4).

Consequently, the main difference between organizational citizenship behavior and attitudes concerning the role and duty is that organizational citizenship behavior is completely voluntary activity and it is beyond the individual role and duty of formal expectations (2). Various types of organizational citizenship behavior are determined in the management literature. For instance, Podsakoff et al. (19) recognized more than thirty different kinds of organizational citizenship behavior. Gardner \& Stough (8) provided a list of common features in all organizational citizenship behaviors, including: volunteering, consciousness, optimistic attitude and advantages taken by both organization and partners. The noteworthy point is when staff develops undesirable attitudes; organizational citizenship behavior would decrease to the low level (13). Organizational citizenship behavior plays an important role in providing service to customers inside and outside the 
organization (6). Meta-analytic studies regarding the relationship between organizational citizenship behavior and effective factors indicate that studies conducted in this filed have commonly focused on four types of factors including: personal characteristics of employees(employees' satisfaction, organizational commitment, justice perception and perception of support by leadership), job characteristics (such as feedback, repetition and internal job satisfaction), organizational characteristics (such as organizational reward and appreciation system and organizational support perception) and leadership behaviors (transformational leadership) (16). Jamali et al. (9) examined the relationship between occupational and organizational factors with organizational citizenship behavior in members of faculty staff teaching at Islamic Azad University branches at the $1^{\text {st }}$ academic zone. They determined to provide an appropriate model indicating that job satisfaction has a significant impact on the organizational citizenship behavior. Rostami et al. (20) in a study titled "organizational citizenship behavior: Explained on the basis of personality, organizational commitment, and job satisfaction of employees at Tehran University" indicated that organizational citizenship behavior shows a significant relationship with job satisfaction and its components (nature of the job, credit, success and responsibility), organizational commitment and its components (emotional commitment and normative commitment), and personality dimensions (Extraversion, agreeableness, responsibility and experience).

Moorman (15) asserts that the relationship between job satisfaction and citizenship behavior depends on the nature of job satisfaction. In other words, it depends on our definition of job satisfaction and the way we measure it. Thus, the importance of job satisfaction is defined based on the cognitive dimension as citizenship behavior prediction factor is considered (based on logical assessments of general conditions and work opportunities)(22).

According to Lambert et al. (12), it is important to identify qualifications of job satisfaction, as well as its effects. In other words, searching for the causes and effects of job satisfaction is more useful and significant than considering it as a comprehensive exogenous variable or final endogenous variable. In addition, it is necessary to develop a comprehensive model for human complex behavior, which has direct and indirect effects on job satisfaction (18).
The results of studies examining the relationship between job satisfaction and organizational citizenship behavior indicate that there is a significant relationship between job satisfaction and its effects on organizational citizenship behavior. Dala (6) found out that there is a positive relationship between organizational citizenship behavior and job satisfaction. AlHussami (1) stated that there is a positive relationship between transformational leadership behaviors and organizational such consequences as organizational citizenship behavior and job satisfaction. Foote \& Li-pingtang (7) found that there is a significant relationship between job satisfaction and organizational citizenship behavior. Kucukbayrak (11) presented that job satisfaction does not lead to a relationship between transformational leadership and organizational citizenship behavior. Sharma et al. (21) found that the increase or decrease in job satisfaction is directly affected by the escalation or diminution in organizational citizenship behavior. Zinabadi (23) established that intrinsic job satisfaction is a dominant and prominent variable affecting organizational citizenship behavior directly and indirectly through organizational commitment intermediary role.

The results of studies conducted by Mehboob \& Bhutto (14)indicates that job satisfaction is a poor predictor of organizational citizenship behavior, and it has a partial influence on altruism dimensions purposes and organizational citizenship behavior modesty.

Studies focused on determining the factors affecting organizational citizenship behavior in the related literature represent that various studies exist in the field of such factors, never the less few researches-conducted in Iran-has focused on the relationship between job satisfaction and organizational citizenship behavior. In the same vein, few studies have considered issues and subjects related to the Youth and Sports Ministry. Since this Ministry is the chief sport organization in the country, its performance affects all dimensions of sport activities including physical training, championship and professional athlete training. Furthermore, the performance of the managers working in this Ministry is the best possible opportunity to support achieving the objectives of physical education and intentions of sport activities. Accordingly, this area needs better attention and several studies are required to be conducted regarding the factors associated with manger's 
performance. Thus, the theoretical framework provided in this study tends to cover this gap. In this piece of research, job satisfaction is considered as independent variable while the organizational citizenship behavior is considered as the dependent variable. Consequently, this study is aimed to assess the relationship between job satisfaction and organizational citizenship behavior of staff working in the Sport and Youth department in the western provinces of Iran. This study has updated an approach, which is different from previously applied research approaches in this field.

\section{MATERIALS \& METHODS}

\section{Research methodology, statistical and sample population}

This study tends to predict organizational citizenship behavior based on job satisfaction components. So, the study is an applied research with correlation method. Statistical population of this research consists of staff working at the provincial department of Youth and Sports in western provinces of Iran. Selected by stratified random sampling method, research sample comprises of 164 people.

Descriptive results showed that out of 164 studied samples, 42 people $(25 \%)$ were single and 122 people $(75 \%)$ were married. In addition, the most frequent subjects were between 31-35 years old $(25 \%)$ and the lowermost age range belonged to samples under 25 years old (0.5\%). Subsequently, by describing demographic characteristics of the studied samples, it was found out majority of the sample population had BA degree $(58 \%)$ and high school diploma was the lowest degree of samples $(2 \%)$.

\section{Research tools}

\section{A) Organizational citizenship behavior questionnaire}

The organizational citizenship behavior questionnaire was used to collect data related to organizational citizenship behavior variable. The applied questionnaire is designed by Podsakoff et al., (19) and it contains 20 questions(5 options) and its scoring method is based on Likert scale (veryhigh:5, very low $=1$ ). Also, the questionnaire is designed based on 5 dimensions including, altruism, responsibility, sportsmanship, civil virtue, respect and admiration. The questionnaire is translated into Persian by Sayyar \& Islami (2007). The questionnaire has also been used in various studies in which its appropriate reliability and validity has confirmed. In a study conducted by Pour Soltani-zarani et al., (2013), sport management professors' corrective comments were used to calculate the questionnaire's validity. Using Cronbach's alpha 76.0, 30 physical education teachers in Mashhad were asked to participate in an experimental study in which internal reliability of organizational citizenship behavior questionnaire was obtained

\section{B) Job satisfaction questionnaire}

In order to assess job satisfaction, Minnesota questionnaire containing 19 questions was used to measure job satisfaction in 6 categories, including Payment System (Questions 1,2,3), occupation type (Questions 4,5,6,7), advancement opportunities (Questions 8,9,10), organizational atmosphere (Questions 11,12), leadership style (questions 13,14,15,16), physical conditions (Questions $17,18,19)$, and scoring which the scoring system are based on Likert scale (strongly agree $=5$ and strongly disagree $=1$ ). The Cronbach's alpha for this questionnaire is reported 0.86 by Bai et al., (2013).The Cronbach's alpha was also used to determine internal reliability of questions in this study. To this end, 164 employees of Youth and Sports departments in the western provinces filled the questionnaires. Then, the questionnaire was analyzed and the Cronbach's alpha coefficient was used to calculate each of the main variables in the study. The results are presented in table 2. Tool reliability is confirmed according to internal reliability coefficients which are presented in table 2 .

Table 1. The Cronbach's alpha coefficients of variables in the study.

\begin{tabular}{ccc} 
& Variable & Cronbach's alpha coefficient \\
\hline 1 & 0.78 & Job satisfaction \\
2 & 0.79 & Organizational citizenship behavior \\
\hline
\end{tabular}

\section{Statistical methods}

Descriptive and inferential statistical methods were used to analyze statistical information of data in this study. First, descriptive analysis of data was presented in the form of frequency tables, mean and standard deviation. Next, Kolmogorov-Smirnov inferential statistic method was used to determine normal distribution of data, and variance analysis. All abovementioned statistical analysis is conducted by using SPSS software, version 16. In addition, all statistical tests are examined significantly $(\alpha=0.05)$. 


\section{RESULTS}

The mean and standard deviation of subjects in job satisfaction and citizenship behavior are presented in the table below.

Table 2. Mean and standard deviation of subjects in research variables.

\begin{tabular}{lcc}
\hline Variables & Mean & SD \\
\hline Job satisfaction & 56.43 & 12.99 \\
Payment system & 7.05 & 2.68 \\
Job type & 24.39 & 3.80 \\
Advancement opportunity & 8.27 & 2.95 \\
Organizational atmosphere & 8.13 & 2.42 \\
Leadership style & 11.75 & 3.17 \\
Physical conditions & 9.06 & 3.21 \\
Citizenship behavior & 69.89 & 9.54 \\
Altruism & 14.85 & 2.93 \\
Loyalty & 10.09 & 2.17 \\
Chivalry & 9.86 & 2.46 \\
Virtue & 9.98 & 2.64 \\
Reverence & 25.11 & 4.58 \\
\hline
\end{tabular}

Regression analysis was used to examine the relationship between job satisfaction and components of citizenship behavior. It must be noted that Perth values were excluded by the computer. Variance analysis results related to citizenship behavior regression on job satisfaction components are presented in the table below.

According to the results, $F$ value (9.415) observed at $(\mathrm{P} \leq 0.01)$ is significant and $26 \%$ of the variance, which is related to citizenship behavior, is explained by the job satisfaction components ( $R 2=$ 0.263). According to significance of citizenship behavior regression on job satisfaction, the coefficients related to prediction equation are presented in the table below.

Regression coefficients of each prediction variable indicate that the payment system and organizational atmosphere ( $\mathrm{P} \leq 0.05)$ may explain citizenship behavior variable variance significantly. Obtained results showed that there is a significant relationship between job satisfaction and organizational citizenship behavior, thus null hypothesis is ignored and rule hypothesis is approved. Therefore, it can be said that there is a positive and significant relationship between job satisfaction and its components and organizational citizenship behavior. According to $t$ statistic, payment system coefficient $(-1.18=B)$ indicates that payment system may predict citizenship behavior changes. This impact coefficient is negative and it means that if a unit is added to optimism score, citizenship score decreases to 2.1. In addition, according to $t$ test, impact coefficient of organizational atmosphere, variable $(1.468=\mathrm{B})$ indicates that the organizational atmosphere variable predicts citizenship behavior changes. The impact coefficient is significant. It means that if a unit will be added to an organizational unit, citizenship behavior score would increase to 47.1.

Table 3. Analysis of variance related to citizenship behavior regression on job satisfaction components.

\begin{tabular}{lcccccccc}
\hline Variance resource & $\mathrm{df}$ & Squares sum & Squares mean & $\mathrm{F}$ & Significant level & $\mathrm{R}$ & $\mathrm{R}^{2}$ & $\mathrm{SE}$ \\
\hline Regression & 6 & 3927.759 & 654.626 & 9.415 & .001 & .513 & .263 & 8.3386 \\
Remaining & 158 & 10986.278 & 69.533 & & & & & \\
Total & 164 & 14914.036 & & & & & & \\
\hline
\end{tabular}

Table 4. Prediction equation coefficients of citizenship behavior using job satisfaction.

\begin{tabular}{|c|c|c|c|c|c|}
\hline Model & Coefficients B & Standard error & Beta standard coefficients & $\mathrm{t}$ & $\mathrm{p}$ \\
\hline Constant value & 55.540 & 3.139 & & 17.691 & .001 \\
\hline Payment system & -1.018 & .291 & -.287 & -3.503 & .001 \\
\hline Job type & .438 & .232 & .175 & 1.893 & .060 \\
\hline Advancement opportunity & .231 & .306 & 072 & .757 & .450 \\
\hline Organizational atmosphere & 1.468 & .291 & .373 & 5.036 & .001 \\
\hline Leadership style & 0.240 & .266 & .013 & .152 & .879 \\
\hline Physical conditions & 0.206 & .252 & .069 & .815 & .416 \\
\hline
\end{tabular}




\section{DISCUSSION}

This study is aimed to investigate the relationship between job satisfaction and organizational citizenship behavior in youth and sports departments of the western provinces in Iran. Accordingly, obtained results indicate that there is a positive and significant relationship between job satisfaction and organizational citizenship behavior. Regression results indicate that job satisfaction affects organizational citizenship behavior and predicts organizational citizenship behavior. The relationship between the satisfaction and organizational citizenship behavior is consistent with findings of Foote \& Li-pingtang (7), Sharma et al. (21), Mehboob \& Bhutto (14), Rostami et al. (20), Jamali et al. (9). Dala (6), Chiu \& Chen (5)and Zinabadi (23) also confirmed the significant relationship between behavior and satisfaction. On the other hand, the obtained results are inconsistent with those found by Kim (10).

Regression results for organizational citizenship behavior prediction based on job satisfaction indicated that job satisfaction is considered as the most important predictive component. Thus, if employees receive sufficient salary and tends to work in their organization, it is predicted that they enjoy proper organizational citizenship behavior and participate in organizations events and meetings. Also, individuals' actions in working environment were beyond determining requirements of the organization. In general, it must be noted that organizational citizenship behavior requires variables that allow behavior incidence. One of the main variables is job satisfaction and such behaviors lead to some consequences in the organization, the most important of which is increased efficiency, performance, positive relationship promotion among staff, more efficiency in resource allocation, reduction of maintenance costs, providing necessary flexibility for innovation and efficient use of resources.

Accordingly, Youth and Sports Ministry must define and target measurement and customer satisfaction as a better pattern for all the staff and try to promote organizational citizenship behavior, since in service organizations, staffs introduce the organization and their attitude affects customer satisfaction and service quality. Obtained results show that better perception of job satisfaction reasons is necessary, and it is related to job satisfaction in the staff. Ability to develop diverse methods for innovation in job satisfaction and developing an extreme process in this field is important in terms of human force significance, to this end, according to obtained results, it is necessary to improve job satisfaction in staff and organizational citizenship behavior to develop organizational citizenship behavior in staff. Thus, according to staff formal role in sports organizations, managers are responsible for job satisfaction in employees to set their goals and objectives and create motivation to achieve objectives.

According to the results of this study, several technical recommendations are offered: leaders can influence on organizational citizenship behavior levels positively on the relevant organization by developing a stronger feeling of job satisfaction. To promote job satisfaction feeling among employees, the minister and his management team must explain the organization vision clearly. This would help staff to kindly accept their responsibility. We can facilitate job satisfaction among employees by goals and roles explanation and rewards. In addition, perception of employees' needs and developing a supporting atmosphere are concerned with job satisfaction. Finally, given the importance of organizational citizenship behavior in organizations' missions, the relationship between job satisfaction and the theoretical framework was studied in this research. Thus, the main aim of this research was to achieve better approaches to study the similar subjects.

\section{REFERENCES}

1. Al-Hussami M. A study of nurses jib satisfaction: the relationship to organizational commitment, perceived organizational support, transactional leadership, transformational leadership, and level of education. European journal of Scientific Research, 2008; 22: 286-295.

2. Allison BJ, Voss RS, Dryer S. Student classroom and career success: the role of organizational citizenship behavior. Journal of Education for Business, 2001; 76: 282-288.

3. Amini B, Rafiee M, Kolaee S. Organizational citizenship behavior Organizational Knowledge Management Magazine, 2007; 24: 64-50.

4. Bienstock C, Demoranville WC, Smith KR. Organizational citizenship behavior and service quality. Journal of Services Marketing, 2003; 17: 357-378.

5. Chiu SF, Chen HL. Relationship between job characteristics and organizational citizenship behavior. Journal of Social Behavior and Personality, 2005; 33.

6. Dala RS. A meta-analysis of the relationship between organizational citizenship behavior and counterproductive work behavior. The Journal of Applied Psychology, 2005;90: 1241-1255. 
7. Foote DA, Li-pingtang T. Job Satisfaction and organizational citizenship behavior: Does team commitment make a difference in self -directed teams? Journal of Management Decision,2008; 46: 932-947.

8. Gardner L, Stough C. Examining the relationship between leadership and emotional intelligence in senior level managers. Leadership and Development Journal, 2002; 23: 6879 .

9. Jamali A, Porzahir AT, Salehi M. The relationship between occupational and institutional factors with organizational citizenship behavior of faculty members of Islamic Azad University in the branches of Region 1 in order to provide an appropriate model. Journal of Leadership and Educational Administration Islamic Azad University of Garmsar, 2009; 3 : 87-106.

10. Kim S. Public service motivation and organizational citizenship behavior in boorea. International Journal of Man Power,2006; 27: 722-740.

11. Kucukbayrak R. An integrative model of transformational leadership organizational commitment job satisfaction and organizational citizenship behavior. Department of Business Administration. Middle East Technical University, 2010; 141.

12. Lambert EG, Hogan NL, Griffin ML. Organizational citizenship behavior and commitment among correctional staff. Criminal Justice and Behavior, 2008; 35: 56-68.

13. Lara ZMD, Rodriguez TFE. Organizational anomie as moderator of the relationship between an unfavorable attitudinal environment and citizenship behavior (OCB): An empirical study among university administration and services personnel. Personnel Review, 2007; 36: 843-866.

14. Mehboob FA, Bhutto N. Job satisfaction as a predictor of organizational citizenship behavior a study of faculty members at business institutes. Interdisciplinary Journal of Contemporary Research in Business,2012; 3.
15. Moorman RH. The relationship between organizational justice and organizational citizenship behavior: Do fairness perceptions influence employee citizenship? Journal of Applied Psychology, 1991; 76: 845-855.

16. Nielsen TM, Hrivnak GA, Shaw M. Organizational citizenship behavior and performance. The Journal of Small Group Research 2009;40.

17. Organ DW, Konovsky M. Dispositional and contextual determinants of organizational citizenship behavior. Journal of Organizational Behavior, 1996; 135:350-339.

18. Park JS, Kim TH. Do types of organizational culture matter in nurse job satisfaction and turnover intention? Leadership in Health Services, 2009;22: 20-38.

19. Podsakoff PM, MacKenzie SB, Paine JB, Bachrach DG. Organizational citizenship behaviors: A critical review of the theoretical and empirical literature and suggestions for future research. Journal of Management, 2000; 26: 513-563.

20. Rostami R, Mahdion-Shalchi B, Narenji-Sani F, Gholami N. Organizational citizenship behavior explained on the basis of personality, organizational commitment and job satisfaction. Contemporary Psychology, 2009; 4.

21. Sharma J, Bajpai N, Holani U. Organizational citizenship behavior in public and private sector and its impact on job satisfaction: a comparative study in Indian perspective. International Journal of Business and Management, 2011; 6: 67-75.

22. Steve W, Mohamed Z, Richard P. Justice and organizational citizenship behavior intentions: faire rewards versus fair treatment. Journal of Social psychology, 2002; 142.

23. Zinabadi HR. The role of career perspectives in organizational citizenship behavior: Test and compare structural patterns. Research and Development Consulting, 2010; 93: 29-54. 